\title{
Talent Management: A Research Based Case Study in the GCC Region
}

\author{
Abhilasha Singh $^{1}$, David B. Jones ${ }^{2} \&$ Nicholas Hall $^{3}$ \\ ${ }^{1}$ American University in the Emirates, Dubai, United Arab Emirates \\ ${ }^{2}$ Founder of The Talent Enterprise, Dubai, United Arab Emirates \\ ${ }^{3}$ Stanford University, Stanford, California, USA \\ Correspondence: Abhilasha Singh, American University in the Emirates, Dubai, United Arab Emirates. Tel: \\ 971-50-514-3415. E-mail: abhilasha.singh@aue.ae
}

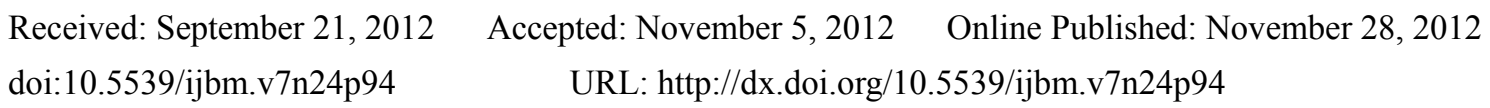

\begin{abstract}
The present case study describes the talent landscape in the Gulf Cooperation Council region, as it exists today.

With unprecedented economic growth and investment in infrastructure by the Government, there is an opportunity to increase the proportion of GCC nationals to engage in private and/or entrepreneurial enterprises. The case describes the various challenges and limitations in talent attraction and retention for private sector companies to compete with government organizations that are able to attract the best talent by paying salary premiums and having a more comprehensive and sophisticated approach to total compensation reward and recognition.

The case on one hand describes the challenges and opportunities in the public versus private sector in the region and on the other hand illustrates the rising expectations and aspirations of national youth population about the job market. The most difficult challenge is for human resources departments to engage the employees. One way of doing so is to customize rewards packages and to consider the interplay among various reward elements. The case highlights how a more differentiated approach to reward on the basis of individual performance and potential is an important next step for human resource practice within the GCC.

In addition, this case examines the challenges of employee engagement in the GCC region while discussing some of the current approaches to enhancing productivity amongst the national (i.e., local) population as well as attracting them to the private sector in particular.
\end{abstract}

Keywords: talent management, management, MENA region, GCC region, MENA, GCC, gulf cooperation council, private sector, hiring, selection, public sector

\section{Introduction}

\subsection{The GCC Talent Landscape}

The countries of the Persian Gulf continue to enjoy an unrivalled, if often unwelcome, degree of international strategic importance. With their huge oil and gas deposits ((representing approximately 60\% of the world's proven reserves (Kapiszewski, 2001)), whether it is the various facets of the ongoing Palestinian conflict, 3 Gulf Wars within the last 20 years or the experience of the "Arab Awakening" in the last 18 months, this situation is unlikely to change in the near future. This case study aims to describe and analyze the impact of population trends and labor market characteristics on the sustained development of the six countries of the Gulf Cooperation Council (the "GCC" which consists of Saudi Arabia, Kuwait, Bahrain, Qatar, the United Arab Emirates, and the Sultanate of Oman). Both aspects are arguably at the heart of the continued viability of the GCC's development model and are arguably currently given too little academic research focus. This is particularly so as these factors are only 2 of the many elements considered in an analysis and understanding of the nature and pace of social and economic activity, with the scarcity and allocation of capital usually being the most important. In much of the Persian Gulf, however, the situation is quite different. The availability and productivity of human capital, and not financial capital, represents the major ongoing restraint on sustained development. Thus, an investigation towards gaining a greater understanding of population and labor market issues as they determine the region's 
overall talent and compensation landscapes represents the most pressing academic, social, and business issue within the GCC at present and indeed for the foreseeable future, with far-reaching implications at a global level.

\subsection{The Unique Challenges Facing Private Sector Employers in the GCC}

Economies across the globe continue to strive to achieve sustainable growth, and as a result, organizational spending on fixed salaries is increasingly under pressure, leading to a real need for alternative mechanisms to reward employees. In addition, increased political focus on executive remuneration and declining profits during a continuing and pervasive worldwide recession will impact bonus funding, further reducing employees' earnings.

Pressure on companies to minimize recruitment and even to rationalize workforces will also present organizations with the challenging task of keeping employees motivated and engaged. This has a particular impact on the talent and reward landscape of the Middle East, which is unique in a number of ways. For instance, 1 in 3 people in the MENA region are between 10 and 24. This "youth bulge" means that those $<30$ years old represent $60 \%$ of the population; the largest ever proportion to enter the job market. Public sector pay increases over the last 12 months have been enormous and pervasive across the region. For example, Qatar announced an increase of $60 \%$ on Basic and Social Allowance for nationals (i.e, the local population) in the public sector ( $120 \%$ if working in the security services), putting pressure on the private sector to follow suit. Saudi Arabia granted public sector workers a $15 \%$ salary increase followed by a $15 \%$ allowance to cope with the rising cost of living. In 2011, minimum wage raised to SR 3,000 and one-time payment of two months' salary declared for all government employees. Oman increased the minimum monthly wage for nationals by $43 \%$ to OMR200. Pensions increased $100 \%$ and a cost of living allowance was introduced. Bahrain granted BHD 1,000 to each local family, increased salaries by $15 \%$ for government employees, and introduced a 'living condition allowance' for employees and retirees. Kuwait shared KD 1,000 with each national citizen as Amiri gift and nationals earning above KD 1,000 received an increase in allowance of KD 50. Finally, Kuwait also raised public sector pay by a further $30 \%$ in the first quarter of 2012 .

According to the Economist Intelligence Unit (EIU), the GCC population is expected to cross the 50 million mark by 2020, up a significant $25 \%$ from the current figure of 40.6 million (EIU, 2010).

Unemployment in the GCC, which rose to $10.2 \%$ in 2011 , is expected to increase to $10.3 \%$ in 2012 , according to the International Labor Organization (ILO, 2011), and this will continue to place pressure on governments to create greater employment opportunities, particularly in the private sector.

While GCC countries are taking slightly different approaches to addressing the employment issue, through schemes such as Nitaqat in Saudi Arabia and Emiratisation programs in the UAE, these are all based upon a quota system for the private sector. At the same time, the cost of skilled labor has been increasing recently due to the high demand for skilled national talent, government regulation, and increasing levels of general inflation.

\subsection{Pressure on Pay in the Short Term (Public vs. Private Sector: Opportunities \& Challenges)}

The public sector salary increases throughout the GCC have created a significant difference between the average earnings of nationals and expatriates. Equally, the gap between public and private sectors is widening, creating disparity in employment and further entrenchment of the currently highly segmented labor markets across the region. More importantly, the already saturated public sector will be unable to absorb more national employees, particularly at the projected rates of population growth. The private sector faces a major challenge in managing budgets and employee expectations. For instance, the IMF notes that the proportion of GCC nationals employed in the private sector has declined across the region by an average of $15 \%$ in the last 20 years. For example, in Saudi Arabia it has declined from 17\% to 10\% between 2000 and 2010 (IMF, 2011). Governments are keen to expand their social spending budgets generally to support further advances in social development and promote political stability. For instance, Saudi Arabia is spending USD 37 billion, specifically targeted at education, healthcare and housing. The Dubai Health Authority is spending enought on healthcare to support pay raises by up to $250 \%$ and hospital beds to double by 2025 . And in Qatar, the education sector will receive QR 19.3 billion in $2011-12$, up $12 \%$ from the previous year.

Increased public sector pay not only makes the private sector less attractive as an employment destination, it also undermines the sustainability of economic development in the region. According to the IMF, Bahrain's break-even oil price was $\$ 114$ per barrel in 2011. This is the highest in the GCC and has increased from around $\$ 80$ per barrel in 2008 (IMF, 2011). According to a report from Jadwa Investment, Saudi Arabia currently needs an oil price of $\$ 74$ per barrel to meet all of its existing annual public sector payment obligations. However, the future projections of current levels of per capita public expenditure against the projections of population growth 
indicate that by 2017 , it will need a break-even per barrel oil price of $\$ 100$ in today's terms. By 2030 this will have risen to $\$ 320$ (Jadwa Investment, 2011).

Pay differentials for nationals (vs. that for expatriates) will likely move in the opposite direction by the end of this decade as the supply of national talent increases exponentially given the current "youth buldge." There will either have to be a painful labour market correction either by a continued move for governments to take action to subsidise nationals' earnings in the private sector or tax expatriates more extensively. The most likely scenario will be some combination of both.

In addition, there is an opportunity to increase the proportion of GCC nationals engaged in entrepreneurial enterprises. This currently has its own challenges and limitations because those businesses already established by older generations enjoy monopoly protection against competition in domestic markets and promotion of their own "rent-seeking" behavior. In addition, recent government policies to foster greater entrepreneurialism amongst GCC nationals may have the opposite effect. This may happen if the organizations cannot be weaned from state support, or weaned from the inherent benefits of the "iqama" system of local sponsorship. Nevertheless, encouraging greater entrepreneurialism has great potential to deliver more employment opportunities for the national population.

Today, the Public Sector Wage Bill represents a significant 10\% of GDP in most of the GCC nations, although nationals currently comprise a minority of the total working population in most member countries (UNDP, 2010). While salary increases are also used as a mechanism to re-distribute wealth among the national population, creating a sustainable future is equally at the forefront of government agendas in the region.

As evidence from the Qudurat study (Aon Hewitt, 2011) suggests, and discussed in more detail below, more than merely focusing on financial rewards to retain talent, it is increasingly important to focus on the broader social and psychological contract between employer and employee. According to the study, the private sector already has a number of comparative advantages over the public sector. For instance, whilst public sector workers, the vast majority of whom are GCC nationals, report greater levels of self-efficacy than their private sector counterparts, the private sector respondents reported greater satisfaction with growth and learning opportunities and a much more positive relationship with their immediate line manager. Whilst employees may be attracted by headline levels of purely pecuniary reward a broader range of elements of employee engagement will be more important in retaining them in the future.

Over the long term, it seems likely that there will be a rationalization and possible reduction in absolute earnings growth to absorb the growing supply of labor due to the youth bulge, as the commercial sector will not have the capacity to recruit more national workers at the current rates. This premium can be significant. For instance, compensation data from the AonHewitt UAE Banking Forum in 2011 (Aon Hewitt, 2011), with 19 participating banks, indicates there is an average guaranteed cash premium of $17 \%$ for staff, $14 \%$ for junior management, $11 \%$ for middle managers and $23 \%$ for senior management roles held by UAE nationals as compared to roles at the same level when held by expatriates.

\subsection{Opportunity for Nationals to Bridge the Employment Gap}

Unprecedented economic growth in key Asian markets over the last decade, particularly in the Indian subcontinent (which contributes the largest proportion of the expatriate workforce in the Middle East) has offered increasingly attractive employment opportunities back home for many. As the traditional supply of expatriates dries up, a gap is left which national talent may be well positioned to bridge as the numbers of those looking for employment amongst that population increases.

However, a recent study from the Hay Group analyzing the views of expatriate managers on the impact of the Nitaqat policy in Saudi Arabia indicated (Hay Group, 2012), there are widespread concerns about the employability and productivity of national talent. At the same time, as the GCC economies continue to develop, organizations must respond by adapting reward strategies adopted by more mature markets, in order to compete for leading talent with specific skill sets in particular levels within organizations in certain industries.

\subsection{Rising Expectations and Aspirations of National Youth and Women}

While the increased spending on infrastructure by governments in the region is a welcome boost to economies, there will be an impact on inflation and therefore compensation in the medium term. Concomitant investment in the human capital is critical towards ensuring the region's development is sustainable in the long-term. Increases in workplace productivity are crucial in order to ensure that a damaging inflationary spiral is not created for labor costs as more GCC nationals enter the workplace at unprecedented rates. It is important that government policies don't remove the incentives for the national population to strive to improve their performance and 
productivity by investing in their own human capital development. This is also important on a psychological level, as well as a purely economic one, as it is important for young GCC nationals to develop not only the most positive and productive behaviors' in their approach to their work, but also that they develop the self-confidence to appropriately believe in their own abilities and match these accurately with their expectations in the workplace.

For instance, a study by Silatech of young Arabs aged 15-29 (Silatech, 2011), revealed that entrepreneurship is an increasingly important topic in the Gulf, and that women were more attracted to start their own business than men. With higher levels of average educational attainment than their husbands and brothers but much lower levels of participation in the formal labor market, the region's women represent the most obvious latent talent pool in the region. Forty-eight percent of the GCC national population is female, and yet the workforce participation rate is only $19.2 \%$ female on average (EIU, 2010). Qatar's National Development Strategy expects female workforce participation rate to reach $42 \%$ by 2016 (EIU, 2010), representing a massive cultural shift for the working culture of the region. While the lowest in the region, women's participation rate in Saudi Arabia has tripled, from $5 \%$ in 1992 to more than $14 \%$ in 2010, with the maximum increase in the banking sector (McKinsey Quarterly, 2011).

Interestingly, according to the study, young potential entrepreneurs were less likely to view their communities as hospitable environments for start-ups and were less likely to trust their governments to allow their businesses to thrive, despite their access to capital and government support more broadly.

There will therefore be more pressure on hiring and compensation budgets on larger private companies. This will be compounded by the growing demands on governments to bring more nationals into the workforce. While the focus on social spending will initially increase employment opportunities, there will be a need to nurture national talent for these roles, and bespoke reward packages will need to be created accordingly.

One consistent theme from the Qudurat (Aon Hewitt, 2011) study is the statistically significant disproportionate motivation national talent derives from titles, designations and level in hierarchy. These "artifacts of status" are an important element of GCC national's satisfaction with their current roles and understanding this offers one way that organizations can seek to manage reward and recognition policies amongst their GCC national staff. Perhaps one of the most noticeable dynamics is the "early mid-career crisis" amongst nationals in middle management positions.

Employee engagement within the region is at its highest for those under 25 and just entering the workforce and then it rapidly falls off a cliff, declining significantly amongst those aged 25-34. Elsewhere in the world, this low-point typically comes later in those aged 35-44. The most likely explanation of this trend is that with GCC nationals in particular, accelerated career development, high expectations of rapid advancement along with a peak in domestic responsibilities at this point, all combine to produce an "early mid-career crisis". This point requires high levels of attention from employers as these are the future leaders of companies, and should be nurtured accordingly, particularly in a working environment where there are also high expectations placed on leaders.

The growing investments being made by governments across the region in education are leading to increasingly higher expectations and aspirations of national youth. The region's youth are distinct in that whilst they typically have high levels of educational attainment by international standards, they have little or no work experience gained from part-time working to supplement their incomes or formal professional development opportunities, as is common elsewhere. Nonetheless, a stronger bridge between education and employment needs to be built, perhaps with more work experience and internship programs being offered.

Holistic development plans and transparent career paths have never been so important and must be created to maintain engagement levels and to navigate these unique dynamics, challenges and issues being faced in the GCC.

A relentless focus on increasing productivity is the key to sustaining a positive and sustainable work environment for the young men and women entering the private sector workplace in the GCC over the next decade. Governments will need to extend and expand investments in both the quantity and quality of educational and training opportunities for GCC nationals. There is an urgent need for individuals, organizations and nations in the region to invest in building human capital and psychological strengths to support and sustain the massive growth witnessed in physical infrastructure and financial investment in the region over the last couple of decades.

Rapidly growing national populations will demand fundamental changes in the workplaces of the GCC 
organizational leaders and HR professionals will need to be prepared to respond accordingly. Population growth and economic growth are related like profitability and financial gearing on a company's balance sheet. When economic growth and productivity gains are being achieved, population growth accelerates the advantages to society-making a good situation better still. However, if economic growth and productivity gains are not secured, population growth can make a bad situation much worse. All the ingredients are in place to establish a more positive, productive and sustainable working culture within the region - the key question is how to get the recipe right?

\subsection{Evolution of Reward and Recognition Practices}

The emphasis on the balance sheet, people management and reward has increased during the current downturn. There has been growing pressure to maximize the utilization of resources across organizations from procurement, to operational costs, and employee output. The focus, particularly in the private sector today is very much on performance and productivity.

The proportion of variable pay has increased substantially to offset the relatively low increases given since the recession began. Similarly, pay linked to performance has become more pronounced as companies seek to retain top talent and ensure sustainability of compensation strategies. Nonetheless, the application of these principles is not always consistent or as rigorously applied as elsewhere in the world.

As commercial organizations seek to 'de-risk' and globalize their operations, we will see international compensation practices begin to influence pay design and structures to a much greater extent within the region.

Although the format and delivery of rewards has changed significantly, and companies are adjusting their strategies accordingly, the fundamental requirements mapped out in Maslow's Hierarchy remain as valid and can be mapped to modern day reward and recognition requirements with focus on growth opportunities, challenging work, and opportunities for learning and development.

\subsection{Total Rewards}

Companies must today present employees with a total rewards solution, rather than individual, isolated reward plans and is a complete value proposition.

Those that manage to do this will maintain a competitive advantage over their peers, by meeting employee expectations and differentiating themselves from the traditional practices employed. Driving performance is becoming increasingly critical. $70 \%$ of new jobs created in the GCC through to 2020 will fall within the services sector (EIU, 2010), making customer service and productivity a key priority. The banking industry, the GCC's single largest private sector source of employment, is expected to expand into high value businesses like asset management and private banking, which follow significantly different compensation structures and have dramatically different performance expectations from the employer's side of the psychological contract than traditional consumer banking.

Furthermore, those that align their rewards packages with their business strategy, typically with an increased focus on margins, productivity and customer satisfaction, will benefit from improved business performance. It is therefore critical to customize rewards packages to an organization's workforce and to consider the integration between each reward element.

\section{Methods}

In order to better understand the evolving requirements for organizations in the GCC to engage and retain talent, a study was conducted to focus on the "psychological capital," as well as the more traditional aspects of pay and managerial satisfaction of the GCC workforce. The study, titled Qudurat (meaning "capabilities" in Arabic), was designed to uncover some of these important psychological aspects of the Arabic and expatriate workforce. A 99-item questionnaire was designed to focus on engagement, positive psychological strengths, and managerial engagement, among other aspects of the worker's orientation. This paper will focus on the differences between the public and private sectors and the psychological aspects of engagement and satisfaction at work.

Specifically, the research question is what are the main differences in the makeup of the workforces of the Arabic and expatriate, as well as the public and private sectors? The answers we find in the study are useful in order to shed light on the interventions and actions that companies and human resources departments can take to engage the Arab workforce, as well as to shore up engagement in the private sector.

In order to gain a broad understanding, a large number of respondents were sought in the public and private sectors of as many GCC nations as possible. Populations were had from the UAE, Qatar, and Bahrain. A very small number of respondents are from Saudi Arabia and Kuwait, which make little impact on the data, and Oman 
was not represented in this survey.

The design of the questionnaire included mostly questions rated on a six-point scale from "strongly disagree" to "strongly agree," with questions on topics such as engagement (e.g., "This organization inspires me to do my best work every day."), psychological strengths like self-efficacy (e.g., "I believe that I can handle any difficulties that come my way at work.") and optimism (e.g., "Whatever can go wrong for me, will go wrong." reverse coded), management (e.g., "My manager is more interested in the success of our team than in his/her own personal success."), and questions about the learning environment of the workplace (e.g., "In my current job, I feel that I am learning and developing my skills and capabilities.”).

\section{Results}

The Qudurat questionnaire was completed by 4,599 workers from 40 companies in the UAE, Qatar, and Bahrain. This constitutes one of the largest psychologically focused workplace questionnaire ever administered in the GCC. $49.4 \%$ of the respondents are male, with $50.6 \%$ female. $51.8 \%$ are from the UAE, $28.2 \%$ are Qatari, and $20 \%$ are Bahraini. As mentioned, a very small number of respondents are from Saudi Arabia (total of 7) and Kuwait (total of 4), which have little impact in the overall data.

We find that workers who are most engaged at work (who score "agree" or "strongly agree" on a six-point scale) are expatriates, $56.9 \%$ are highly engaged, versus nationals who score only $50.8 \%$ highly engaged. Men are more engaged at work than women, $57.3 \%$ versus $49.7 \%$ highly engaged. Most importantly, female nationals are the least engaged demographic, at $48.4 \%$ highly engaged. Compared to Aon Hewitt's worldwide scores of workplace engagement on this metric, these are some of the lowest scored recorded of a major demographic.

It is important to pay attention to the how engagement among the national workforce operates among age ranges in order for companies to prepare for the coming "youth bulge" and how to predict to handle it. The Qudurat study shows that nationals less than 25 years old are the most engaged at work at $63.6 \%$. From there, the numbers drop drastically. Twenty-five to thirty-four year old nationals are only $45.1 \%$ highly engaged, the 35-44 age range is $48.8 \%, 45-54$ is $58.6 \%$ and the 55 and above range is $58.7 \%$. What this data show is that among the Arab population, there is a dramatic dip in engagement which can be caused by a number of factors, specifically lack of support in higher-responsibility positions, as well as home life pressures of young families.

The identity that nationals hold to their Arab roots is quite strong, and this shows in the data how much the Arab identity influences the approach to work. Sixty-five percent of nationals scored "strongly" or "very strongly" on a six-point scale to the question "How strongly does your national or religious identity influence your approach to work?" This is nearly double that of expatriate response to this question (35\% answered "strongly" or "very strongly"). This has the implication that private foreign companies must keep the Arab identity in mind when aiming to develop an engaged Arabic workforce.

\section{Discussion}

Considering that an extremely high percentage of the public sector is made of up national workers, we can see just how important it is for the private sector, if they want to remain competitive, to focus on the orientation of the Arab identity, and particularly females. Females constitute slightly more than half of the workforce, and that percentage will only grow, along with the coming "youth bulge."

\subsection{Limitations of the Current Research}

There are several limitations to the current research that must be addressed. Firstly, Saudi Arabia and Oman are not represented in this survey. In order for questions regarding the Arabic GCC working population to be answered with greater representation, responses need to be had from both Saudi Arabia and Oman. Saudi Arabia in particular would be an important population to have representation considering its size in relation to the rest of the GCC, as well as its influence it has in the region.

Secondly, one of the largest populations in this survey come from Bahrain, and it is exclusively from the public sector. Therefore, the private sector is not represented at all in Bahrain and lopsidedly represented in the current study, as only the UAE and Qatar provide private sector representation.

Given these obvious limitations, this study still represents one of the largest surveys in the region of the Arabic and expatriate workforce in the GCC. Given the size of the sample, the current research still has considerable weight in its conclusions and need to be seriously considered by those managing workforces within the GCC region.

Future research will focus on gathering a more representative sample of the GCC, by targeting Saudi Arabia and Oman heavily, and making inroads in the private sector in Bahrain. More importantly, the move of the "youth 
bulge" into the workforce in the coming years must be addressed. Expectations and attitudes of students of the region today will translate into the expectations and attitudes of the workforce tomorrow - both public and private sectors. Designs are already underway for a survey of students in the education sector to understand the orientation of the current population so that workplace interventions can be implemented before and after their arrival to ensure their productivity and engagement.

\subsection{What will Drive and Influence Compensation and Rewards for Nationals in the Region?}

As the supply of GCC nationals entering the labor market increases rapidly over the next decade, salary levels are likely to become more moderated over time and the dependence on cash compensation will be reduced. The pressures on the labor market will need to be accommodated in the private sector through more innovative employment and compensation practices.

At the same time, this presents both opportunities and challenges. While this scenario will encourage diversity in both sectors and functions, it will also necessitate flexibility in employment and reward propositions.

Current trends, the business environment and the talent landscape will all affect the dynamic. Compensation and rewards will be driven by:

- Evolving government policy

- Workplace attitudes and behaviors

- Expectations and aspirations

- Demand and supply of talent

- Salary budgets

- Advancing productivity and engagement

4.3 Changing Structure of Rewards: Shift from Remuneration to Total Rewards

With the changing economic scenario and evolving demographics in the region, greater focus on productivity, rising health care costs and squeezing reward budgets, most organizations' approaches to rewarding national talent will begin to evolve as getting the right reward and recognition to the right people has never been more challenging.

The Qudurat (Aon Hewitt, 2011) study pointed to "career growth" and "learning and development" as being the top two engagement drivers for nationals, followed by "pay and benefits" as the third most important driver of engagement. Thus, organizations will be compelled to move away from an over-reliance on cash - based compensation alone, to a richer, more balanced employment deal, where the different components of an employee's reward package reinforcing each other, that helps attract, engage and retain national talent and ultimately, creates sustainable value for the organization.

\subsection{Becoming an Employer of Choice}

Employee engagement in the GCC has typically been at low levels by international comparisons. Only in the last year or so, according to the Qudurat report (Aon Hewitt, 2011), has the average level of employee engagement in Europe fallen below that of the GCC. A fundamental change in employee rewards will help to reduce pressure on public sector cash compensation and manage the large workforce by creating multiple avenues to reward employees.

\subsection{Benefits to the Employer}

- Lower fixed costs and organizational risk

- Balance costs and perceived value of compensation and benefits

- Improve employee attraction and retention

- Increase employee performance and productivity

- Improve competitive positioning

4.6 Steps towards Becoming an Employer of Choice

1) Closely align reward programs with company goals, e.g. through a greater focus on contribution

2) Communicate pay objectives and reward employee behavior to meet performance expectations

3) Implement pay for performance to focus on national talent whom display high potential

4) Reward employees' consciousness of status or compensation premium through alternative recognition 
vehicles that meet expectations

5) Identify succession paths and develop business continuity with national talent identified and nurtured within the organization

6) Encourage more women to enter the workforce through flexible working, equal qualification for benefit programs and continuing education

7) Address aspirations of the employable youth through innovative and progressive reward propositions and work practices

Expatriate workers currently hold an overwhelming majority of private sector jobs across the GCC (Booz and Co, 2010). Decades of reliance on imported labor have generated deeply entrenched views about many private sector careers as unattractive to nationals, precisely because they are associated with challenging working conditions. In turn, many private sector employers expect to receive more output from expatriates in terms of working hours than they would from nationals.

More importantly, there is a need to professionalize blue-collar work and afford it the status it receives elsewhere as a craft. This is a critical step if more GCC nationals are to be encouraged into entrepreneurialism in particular. The relative success of Oman and Bahrain in this respect could provide a useful role model across the GCC. This could be combined with supporting smaller, owner-managed businesses as an engine of job creation, productivity and innovation.

\section{Conclusion}

\subsection{Employee Engagement Matters}

Decades of research in the areas of employee motivation and engagement have demonstrated that organizations that achieve higher levels of engagement are associated with better business results, including improved organizational performance and an increased level of customer service. This creates longer-term value for stakeholders. In a nutshell, engaged employees are more driven and willing to exert additional, discretionary effort towards supporting the success of their organizations. Achieving higher levels of employee engagement in the Middle East matters significantly especially as it is one of the fastest growing regions in the world, economically and demographically. It is imperative to ensure that the current and future cohorts of employees joining the workforce are capable, motivated and engaged to deliver high levels of performance to facilitate the pace of development.

Nonetheless, current approaches to employee engagement are too reliant on correlations and associations with overall organizational performance alone. In addition, on a conceptual level, too many engagement models ignore that it is a two-way process. Employee engagement, just like marriage, is a matching and "a meeting of true minds", to quote Shakespeare. If HR professionals only ask questions about how satisfied employees are with what the organization does for them or to them we are only getting half the picture at best. We must understand more about the attitudes, strengths and expectations which employees bring with them to work every day and how well they match, or not, what the employer is offering. Employee engagement in its true sense is a two-way process closely related to the psychological contract. Finally, for HR professionals and organizational leaders in particular, it is critical that human capital development practices support further acceleration of economic growth. This means that triggers for engagement, motivation and productivity must move from mere associations and correlations to more powerfully predictive regression analysis in order for organizational development to shift forward on a way which will allow the GCC's private sector to develop the financial capacity to accommodate the growing needs of the region's workforce.

\section{References}

Al Yahya, K. (2008). The Over-Educated, Under-Utilized Arab Professional: Why Doesn't Human Capital Development Bring Desired Outcomes? Dubai School of Government Working Paper Series, No. 08 - 0.

Aon Hewitt. (2011). Qudurat Report.

Richard S., \& Hatem S. (2010). Meeting the Employment Challenge in the GCC: The Need for a Holistic Strategy. Retrieved from http://www.booz.com/media/uploads/Meeting_the_Employment_Challenge_in_the_GCC.pdf

Economist Intelligence Unit. (2010). The GCC in 2020: Resources for the Future: A Report from the EIU. Sponsored by the Qatar Financial Centre Authority. 
Forstenlechner, I., \& Rutledge, E. (2010). Unemployment in the Gulf: Time to Update the Social Contract. Middle East Policy, 17(2), 38-51.

Hay Group. (2012). Nitaqat in the Spotlight. Retrieved from http://www.haygroup.com/uae/downloads/details.aspx?id=33248

IFC World Bank Group. (2011). Education for Employment: Realizing Arab Youth Potential. Retrieved from http://blogs.worldbank.org/education/education-for-employment-realizing-arab-youth-potential

International Council on Security and Development. (2010). Unemployed Youth in the UAE, Personal Perceptions and Recommendations. Retrieved from http://www.icosgroup.net/2010/report/unemployed-youth/

International Labour Organisation. (2011). Global Employment Trends. Retrieved from http://www.ilo.org/wcmsp5/groups/public/@dgreports/@dcomm/@publ/documents/publication/wcms_1504 40.pdf

International Labour Organisation. (2009). Growth, Employment and Decent Work in the Arab region: Key Policy Issues, Arab Employment Forum. Retrieved from http://www.ilo.org/public/english/region/arpro/beirut/downloads/aef/growth_eng.pdf

International Monetary Fund. (2011). Regional Economic Outlook, Middle East and Central Asia. Retrieved from http://www.imf.org/external/pubs/ft/reo/2011/mcd/eng/pdf/mreo0411.pdf

Jadwa Investment. (2011). Saudi Arabia's coming oil and fiscal challenge. Retrieved from http://www.susris.com/2011/07/30/saudi-arabias-coming-oil-and-fiscal-challenge/

Kapiszewski, A. (2006). Arab Versus Asian Migrant Workers in the GCC Countries, Population Division. Department of Economic and Social Affairs, United Nations Secretariat, New York, pp.2-16.

McKinsey Quarterly. (2011). Linking Jobs and Education in the Arab World (Original Source - Global Insight).

Middle East Youth Initiative. (2010). Missed by the Boom, Hurt by the Bust: Making Markets Work for Young People in the Middle East: An Agenda for Policy Reform and Greater Regional Co-Operation. Retrieved from http://www.brookings.edu/research/reports/2009/05/middle-east-youth-dhillon

Niblock, T., \& Malik, M. (2007). The Political Economy of Saudi Arabia. Routledge, London and New York.

Silatech. (2011). The Silatech Index: Voices of Young Arabs (report in collaboration with Gallup). Retrieved from http://www.silatech.com/docs/silatech-index/the-silatech-index-voices-of-young-arabs.pdf?sfvrsn=8

The Economist. (2012). The Other Arab Spring: Entrepreneurs in the Arab World are Leaping into Action. Retrieved from http://www.economist.com/node/21560243

UNDP. (2010). ADHR Population Levels, Trends and Policies in the Arab Region: Challenges and Opportunities. Retrieved from http://www.arab-hdr.org/publications/other/ahdrps/paper01-en.pdf

UNDP. (2002, 2003, 2004 \& 2005). The Arab Human Development Report.

World Bank. (2004). Middle East and North Africa. Annual Report, Washington D.C. 


\section{Appendix}

The Arab world's employable population will grow dramatically over the next 10 years.

2010 population of Arab world ${ }^{1}$ (estimated), millions

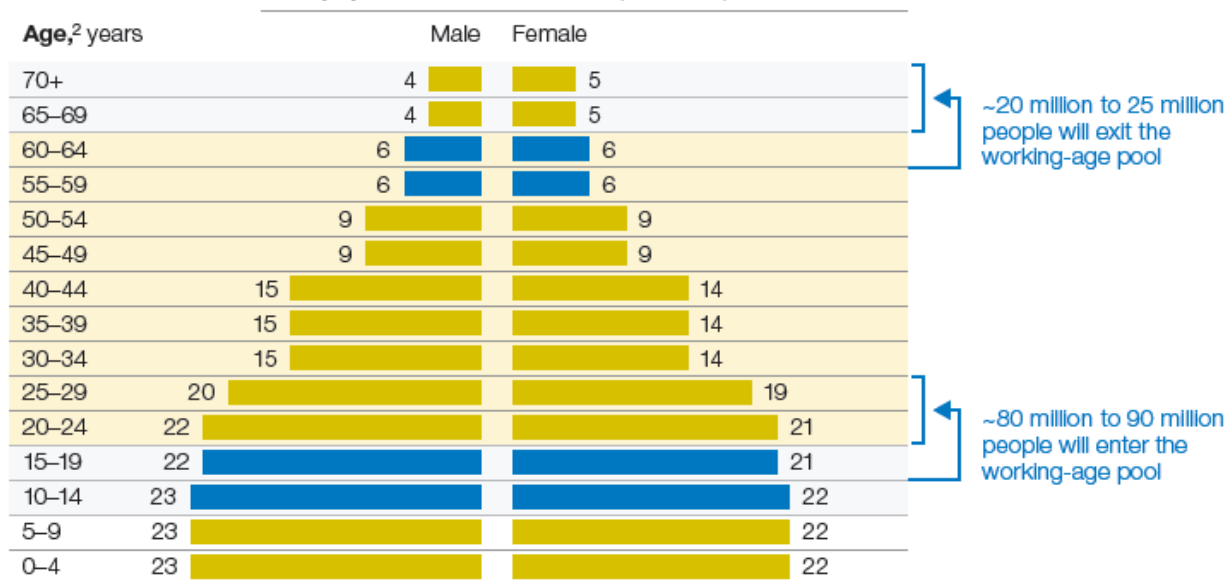

${ }^{1}$ Arab world comprises the 22 nations in the League of Arab States.

${ }^{2}$ For age groups where data are not given in 5-year increments, an even split was used as an estimate. Source: Global Insight

Figure 1. Arab world population profile

Source: From McKinsey Quarterly, "Linking Jobs and Education in the Arab World", April 2011 (Original Source - Global Insight)

(A) Population under 30

Q Youth Unemployment $(>25)$

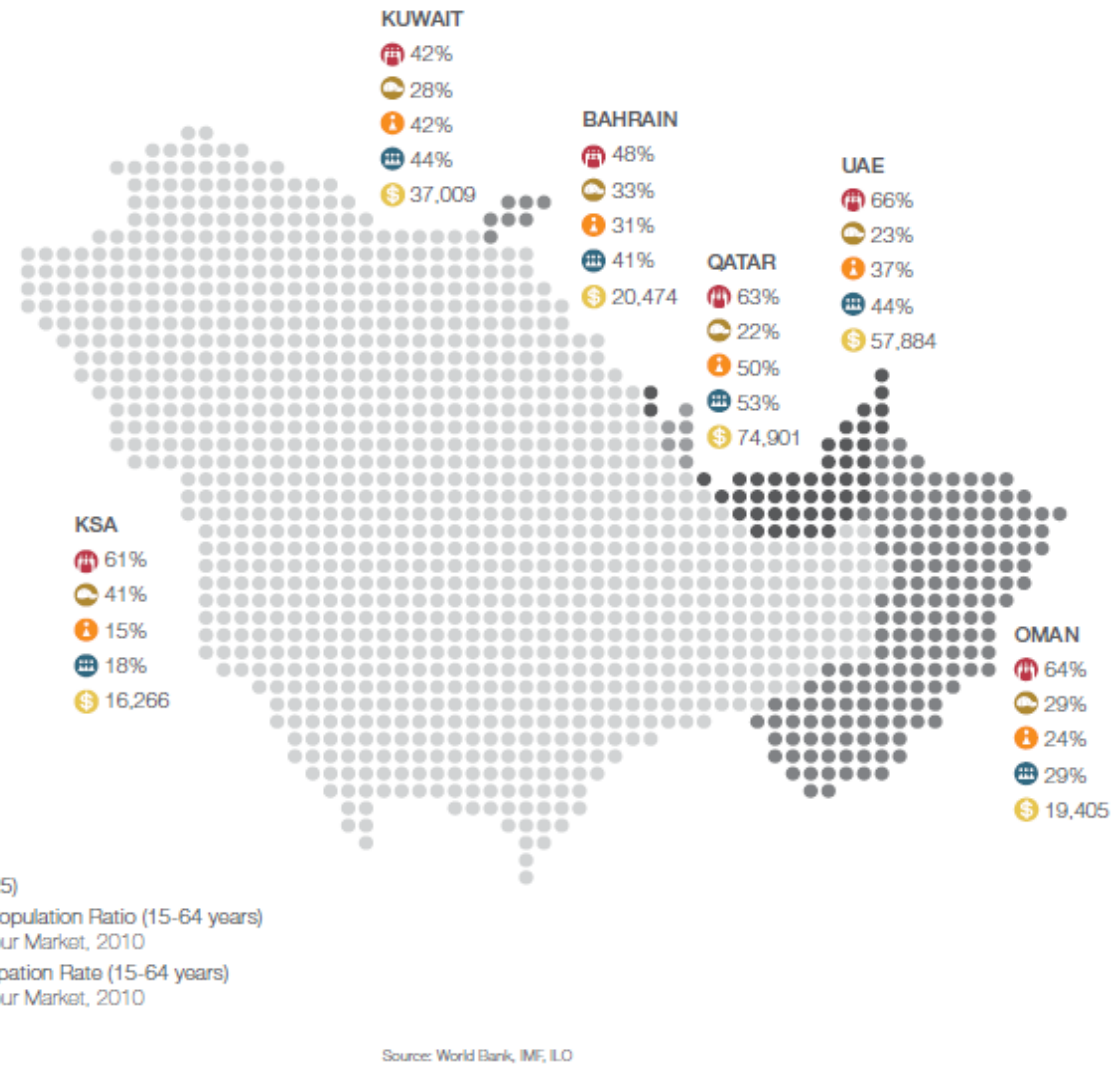

Figure 2. Key economic indicators in the GCC

Source: Aon Hewitt Qudurat Report, November 2011 (Original Data Source - World Bank, IMF, ILO) 


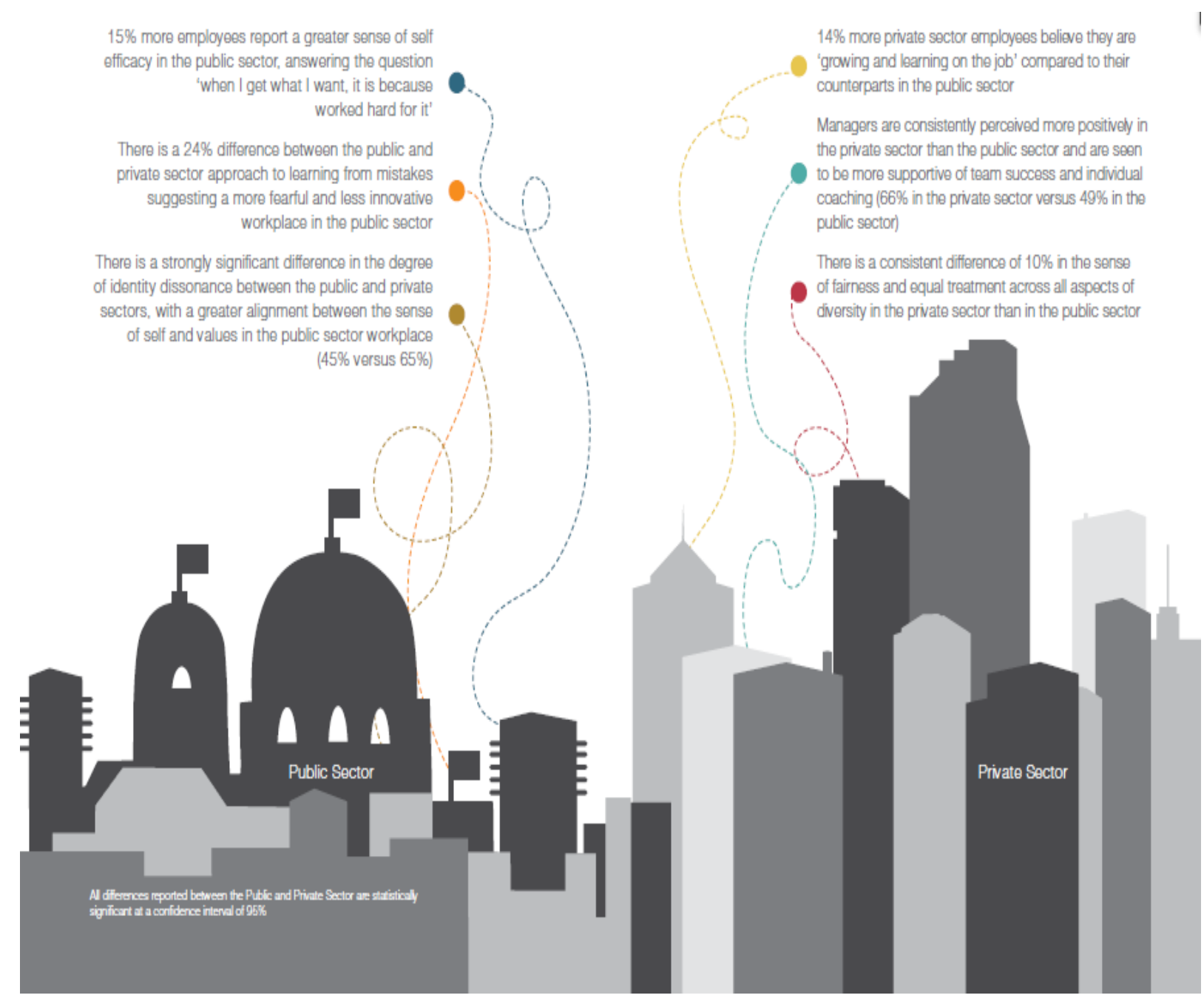

Figure 3. Public and private sector work orientation differences in the GCC

Source: Aon Hewitt Qudurat Report, November 2011 


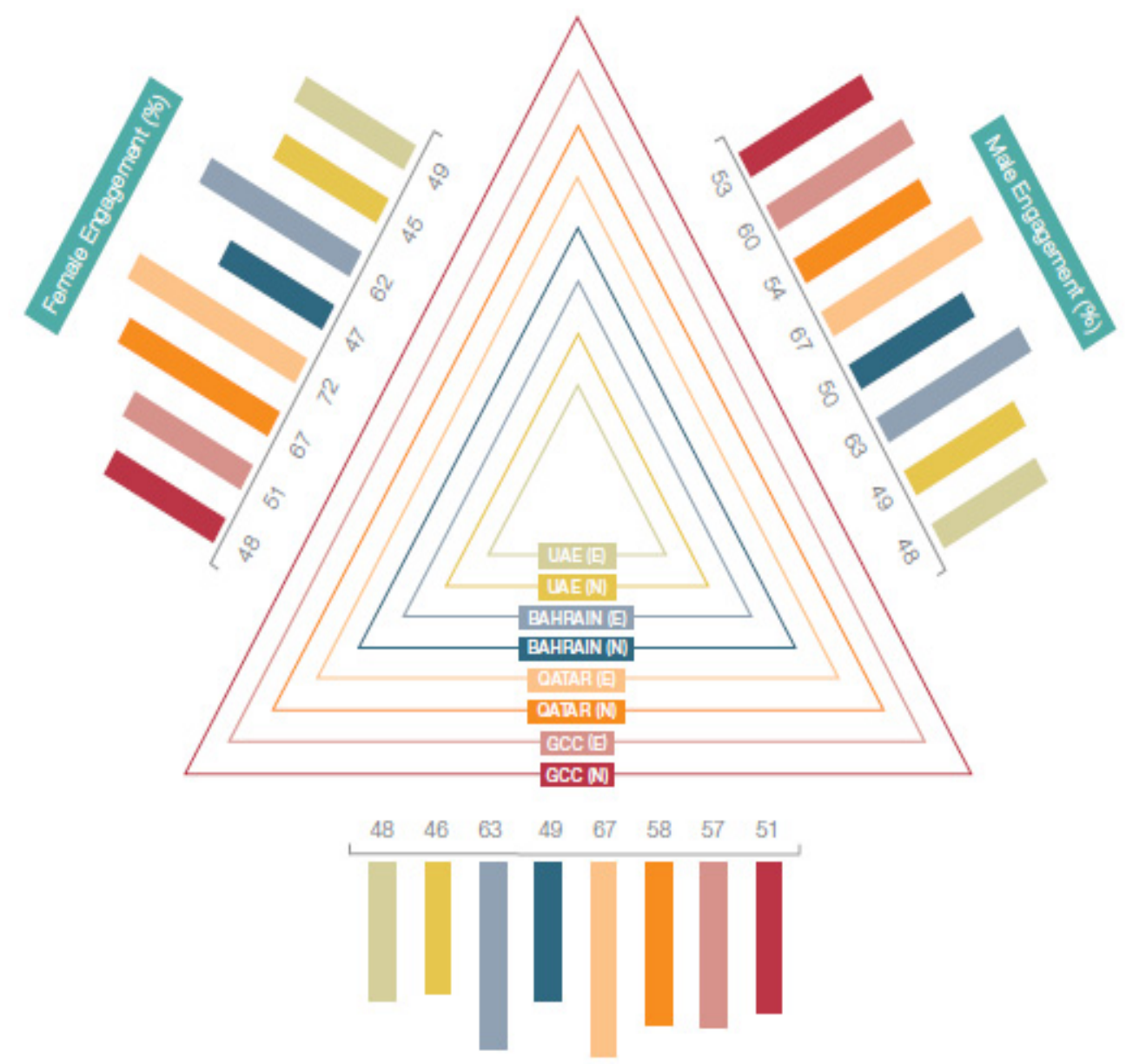

Overal Engagament (\%)

GCC and Courty - wise engrgemert data bsaed on Qudurnt' research study

reported for Nationals (N) and Expatristes (E)

Figure 4. Employee engagement differences by gender and country (for nationals and expatriates)

Source: Aon Hewitt Qudurat Report, November 2011 


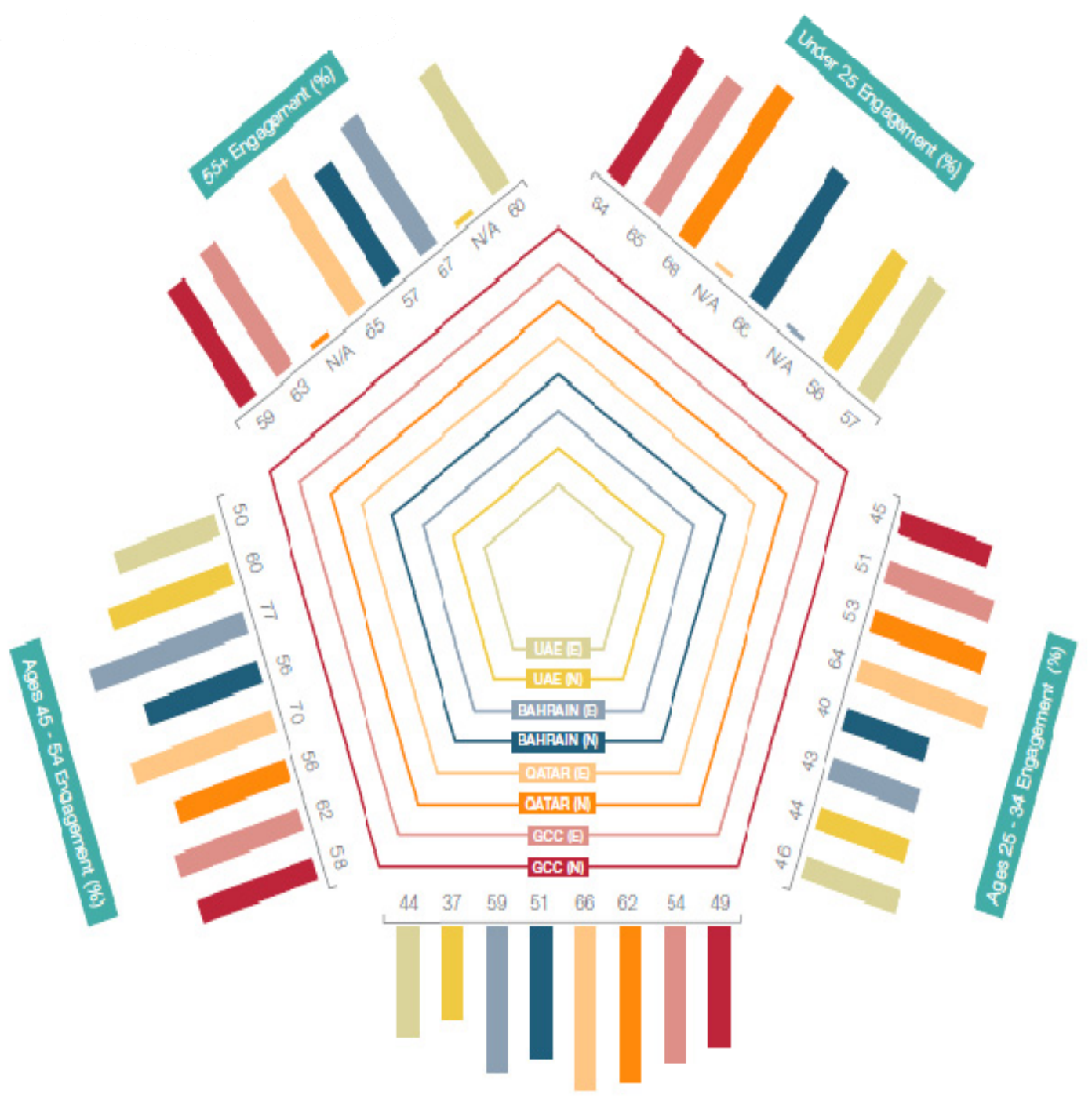

GCC and Courtry wise engagernent data based on Oudurn 'T research study reported for Ntrionds $(\mathrm{N}$ ) and Expatrivies (E)

Figure 5. Employee engagement differences by age cohort and country (for nationals and expatriates) Source: Aon Hewitt Qudurat Report, November 2011 


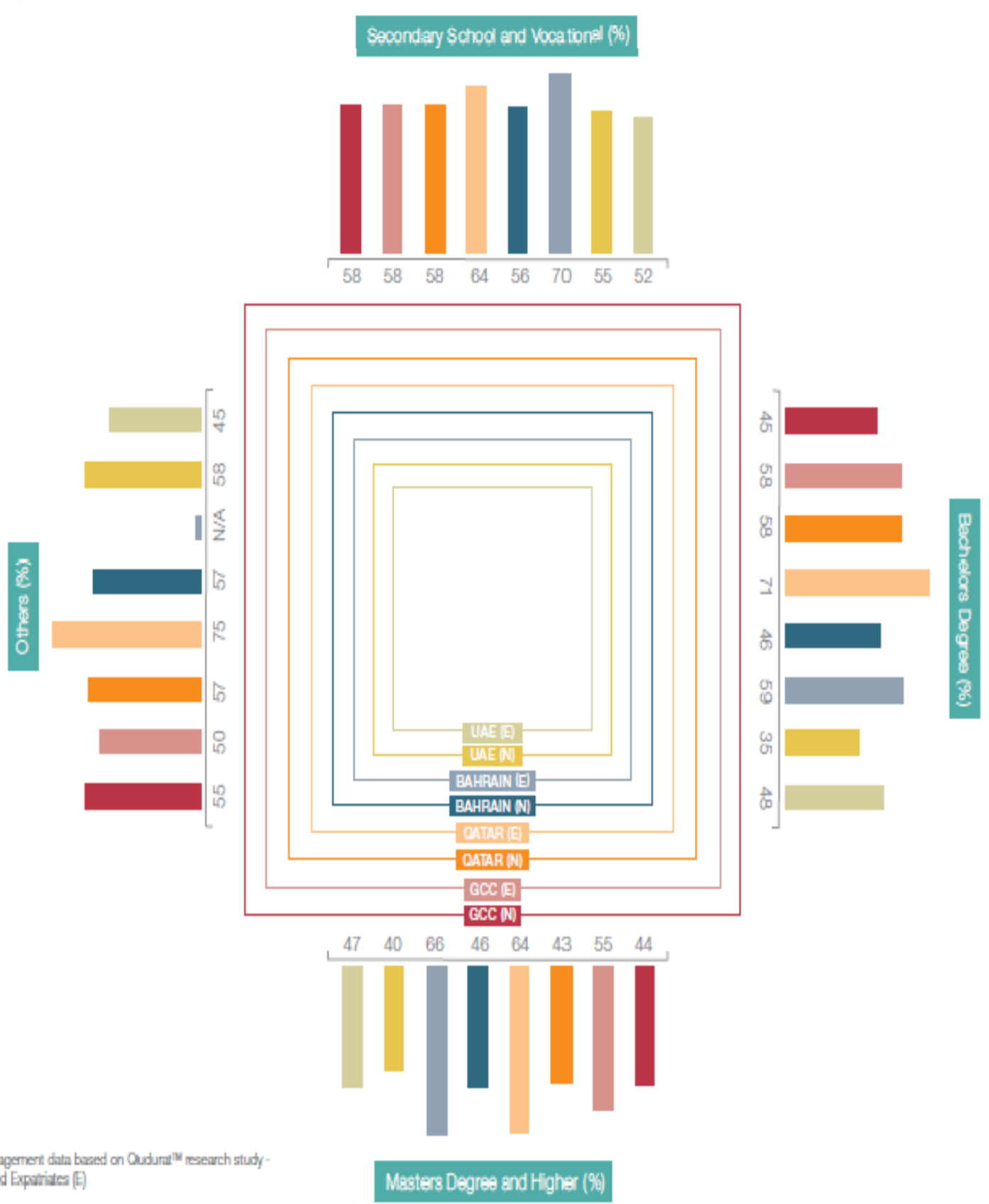

GOC and Courtsy - wise engagemert dath boaed on Qudurat 'W research study requrtad for Nationiala $\mathrm{N}$ ) and Expatriter (E)

Figure 6. Employee engagement differences by educational qualifications and country (for nationals and expatriates)

Source: Aon Hewitt Qudurat Report, November 2011 